\title{
Mitochondrial inclusions in fibroblast culture from a patient with $\beta$-methylcrotonylglycinuria
}

\author{
J. McLEAN* and G. STEWART $\dagger$
}

\begin{abstract}
Summary. Electron microscopy of fibroblasts grown from a patient with biotin responsive $\beta$-methylcrotonylglycinuria revealed unusual deposits within their mitochondria.
\end{abstract}

The clinical and biochemical findings in a patient with $\beta$-methylcrotonylglycinuria have been described by Gompertz et al (1971) and Gompertz and Draffan (1972). Briefly the patient at 5 months of age presented with metabolic acidosis and ketosis. $\beta$-Methylcrotonylglycine, $\beta$-hydroxyisovaleric acid, and tiglylglycine were found in the child's urine. Clinical improvement and disappearance of the metabolites from the urine occurred with the administration of biotin, a cofactor for $\beta$-methylcrotonyl CoA carboxylase.

In this study, skin fibroblasts from the patient and his parents were grown in culture and examined by electron microscopy.

\section{Materials and methods}

Skin biopsies were performed on the patient at the age of 9 months-after biotin treatment had been startedand on his parents.

Fibroblasts were grown in $10 \%$ newborn calf serum and Eagle's medium; the culture was divided by trypsinization five times before preparing cells for electron microscopy. It is unlikely that any biotin in the original biopsy persisted after these multiplications.

Cells subcultured into Leighton tubes were prepared for electron microscopy when confluent. Cultures were fixed in situ with $2 \%$ glutaraldehyde in $0.05 \mathrm{M}$ cacodylate buffer $\mathrm{pH} 7.2$ at $4^{\circ} \mathrm{C}$ for three hours and washed overnight in $0.1 \mathrm{M}$ cacodylate buffer containing $4.5 \%$ sucrose. They were then treated for one hour in $1 \%$ osmium tetroxide in $0.05 \mathrm{M}$ cacodylate buffer containing 5\% sucrose. Cells were dehydrated in ethanol and embedded in Araldite.

Sections were cut using a Porter-Blum MT2 Ultramicrotome, stained with methanolic uranyl acetate and

\footnotetext{
Received 7 December 1973.

* Department of Neurology, Royal Free Hospital.

+ MRC Human Biochemical Genetics Unit, Galton Laboratory, University College, London. Present address: Division of Inherited Metabolic Diseases, Clinical Research Centre, Northwick Park Hospital, Harrow, Middlesex.
}

lead citrate and viewed in a Siemens 101 electron microscope at $80 \mathrm{kV}$.

\section{Results}

Mitochondria in the culture from the patient contained amorphous deposits of an unidentified material (Fig. 1). This was often associated with derangement of the mitochondrial cristae in the neighbourhood of the deposits. Similar but less marked abnormalities were seen in the cultures from both parents.

Deposits of this nature have not appeared in examining 60 other cultures from skin biopsies on normal subjects and on patients with a variety of neurological diseases. Fig. 2 shows a mitochondrion from a normal fibroblast culture.

\section{Discussion}

Such mitochondrial abnormalities have not previously been reported in fibroblast cultures. Mitochondrial abnormalities have been noted in a wide variety of muscle diseases. Many of these are reports of crystalline, lamellar, or rod-shaped inclusion bodies in the muscle mitochondria (discussed by Mair and Tomé, 1972). Salmon, Eseri, and Ruderman (1971) described rounded electron-dense mitochondrial inclusions in the muscle of a myopathic patient who had hyperglycaemia and hyperketonaemia.

Amorphous mitochondrial inclusions, similar to those described in this study, were illustrated in the description of axonal dystrophy produced by vitamin E deficiency in the rat by Schochet (1971). Other reports of mitochondrial inclusion bodies seem associated with various types of cell injury or necrosis (Svoboda and Higginson, 1963; Minick et al, 1965; Trump, Goldblatt, and Stowell, 1965; Gritzka and Trump, 1968). 


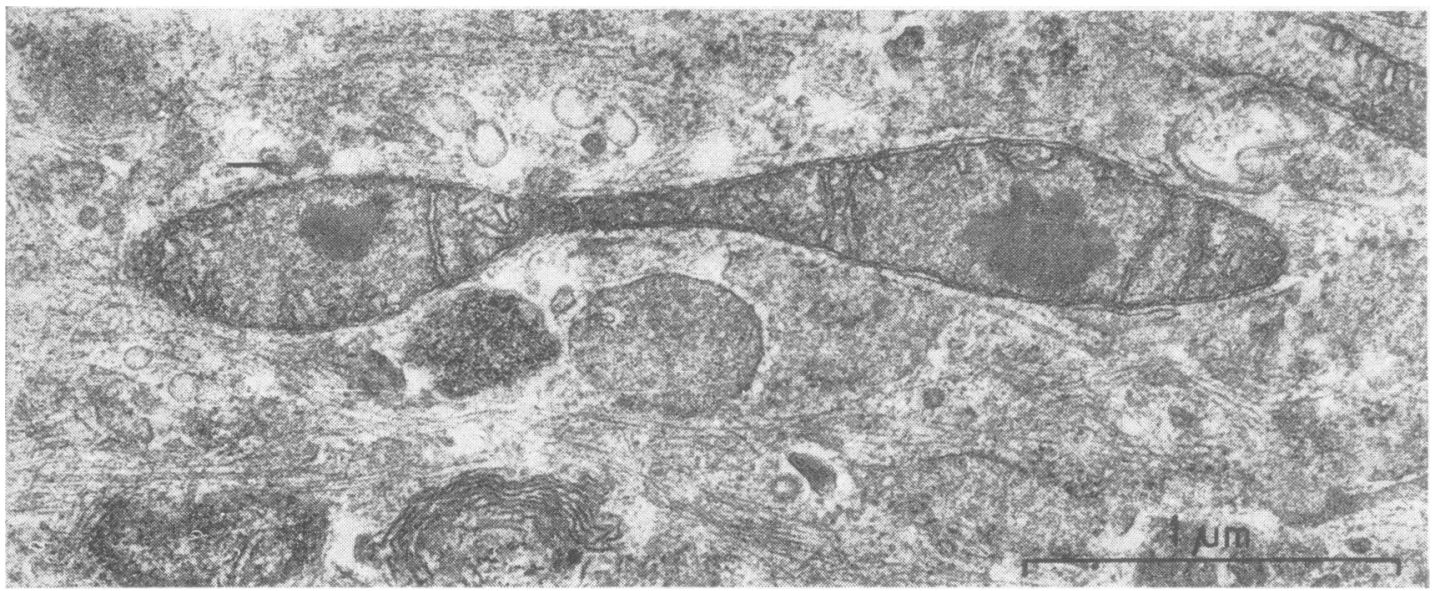

FIG. 1. $\beta$-Methylcrotonylglycinuria: amorphous deposits in a mitochondrion of a fibroblast cultured from the patient.

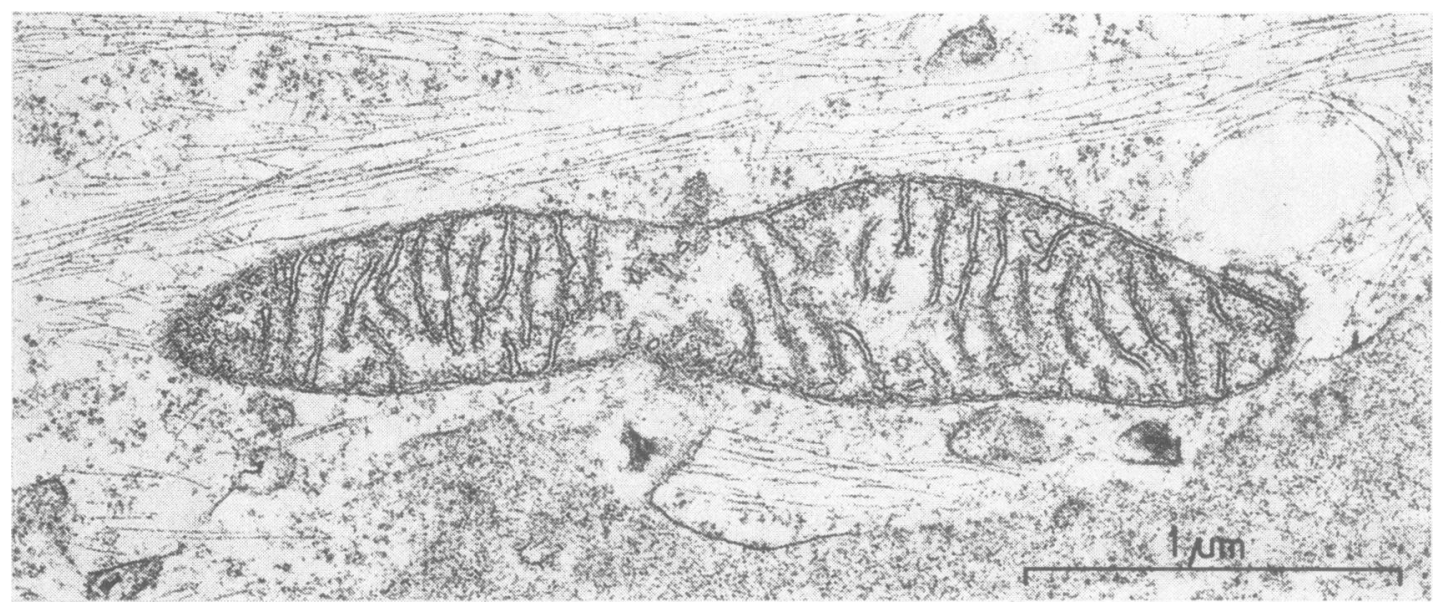

FIG. 2. Control culture: a mitochondrion from a normal fibroblast culture.

The occurrence of mitochondrial deposits in cells cultured from a patient with $\beta$-methylcrotonylglycinuria is interesting since the presumed enzyme defect (of $\beta$-methylcrotonyl CoA carboxylase) is of a mitochondrial enzyme. The less marked changes found in cultures from the patient's parents may indicate that they are heterozygotes and that the disease is recessively inherited.

We thank Drs D. Hull and D. Gompertz for their help and cooperation and Miss J. Workman for technical assistance. Dr J. McLean received a grant from the National Fund for Research into Crippling Diseases.

\section{REFERENCES}

Gompertz, D. and Draffan, G. H. (1972). The identification of tiglylglycine in the urine of a child with $\beta$-methylcrotonylglycinuria. Clinica Chimica Acta, 37, 405-410.

Gompertz, D., Draffan, G. H., Watts, J. L., and Hull, D. (1971). Biotin-responsive $\beta$-methylcrotonylglycinuria. Lancet, 2, 22-24.

Gritzka, T. L. and Trump, B. F. (1968). Renal tubular lesions caused by mercuric chloride. American fournal of Pathology, 52, 1225-1277.

Mair, W. G. P. and Tomé, F. M. S. (1972). Atlas of the Ultrastructure of Diseased Human Muscle. Churchill Livingstone, Edinburgh.

Minick, O. T., Kent, G., Orfei, E., and Volini, F. I. (1965). Nonmembrane enclosed intramitochondrial dense bodies. Experimental and Molecular Pathology, 4, 311-319. 
Salmon, M. A., Eseri, M. M., and Ruderman, N. B. (1971). Myopathic disorder associated with mitochondrial abnormalities, hyperglycaemia and hyperketonaemia. Lancet, 2, 290-293.

Schochet, S. S. (1971). Mitochondrial changes in axonal dystrophy produced by vitamin E deficiency. Acta Neuropathologica, Suppl. No. 5, pp. 54-60.
Svoboda, D. J. and Higginson, J. (1963). Ultrastructural hepatic changes in rats on a necrogenic diet. American fournal of Pathology, 43, 477-495.

Trump, B. F., Goldblatt, P. J., and Stowell, R. E. (1965). Studies on necrosis of mouse liver in vitro. Ultrastructural alterations in the mitochondria of hepatic parenchymal cells. Laboratory Investigation, 14, 343-371. 